\title{
Design emocional: através dos objetos, das coisas e dos semióforos
}

\section{Emotional design: through objects, things and semiophore}

\author{
Laiana Pereira da Silveira[1], Frantieska Huszar Schneid \\ Moreira (orientadora) ${ }^{[2]}$
}

\begin{abstract}
Resumo: Este trabalho apresenta um recorte da pesquisa de conclusão de curso “MODA E MEMÓRIA: A construção de uma coleção de moda a partir das memórias afetivas vinculadas a objetos pessoais" defendido no curso Superior de Tecnologia em Design de Moda do Instituto Federal Sul-rio-grandense campus Pelotas Visconde da Graça no mês de junho de 2018. O presente artigo tem como objetivo principal mostrar através de uma reflexão, como o design emocional e os objetos que estão a nossa volta, contribuem para a construção das nossas memórias afetivas. Através de uma pesquisa bibliográfica e da utilização dos dados coletados por meio de um questionário, pode-se analisar e exemplificar com relatos verídicos, o estudo em questão, escolhendo um exemplo pessoal e um relato obtido por questionário.
\end{abstract}

Palavras-chave: Design emocional. Objetos. Coisas. Semióforos. Memórias afetivas.

Abstract: This paper presents a review of the course conclusion research "FASHION AND MEMORY: The construction of a fashion collection from the affective memories related to personal objects" defended in the Superior course of Technology in Fashion Design of the Federal Institute Sul-rio- grandense campus Visconde da Graça Pelotas in the month of June 2018. The main objective of this article is to show through a reflection, as the emotional design and the objects that are around us, contribute to the construction of our affective memories. Through a bibliographical research and the use of the data collected through a questionnaire, one can analyze and exemplify with truthful reports, the study in question, choosing a personal example and a report obtained by questionnaire.

Keywords: Emotional design; objects; stuff; semiophores; affective memories.

[1] Tecnólogo em Design de Moda, IFSUL. laianasilveira@gmail.com

[2] Doutorado em em Memória Social e Patrimônio Cultural

(em andamento), UFPEL.frantieskahs@gmail.com 


\section{INTRODUÇÃO}

Este artigo é um recorte da pesquisa de trabalho de conclusão de curso intitulada "MODA E MEMÓRIA: A construção de uma coleção de moda a partir das memórias afetivas vinculadas a objetos pessoais", defendida em junho de 2018 no curso Superior de Tecnologia em Design de Moda, do Instituto Federal Sul-rio-grandense Campus Pelotas Visconde da Graça.

O objetivo principal desta pesquisa é trazer a reflexão de como é feita a construção das nossas memórias afetivas e como os nossos objetos pessoais contribuem para isto, e o recorte aqui apresentado é o do significado dos objetos, relacionando a um novo fator que é o design emocional.

Para começar a tratar do assunto e ligá-lo ao "design emocional", trago aqui o conceito de Cantelli a respeito do assunto (2009 apud OLIVEIRA, 2017, p. 106), o autor afirma que "qualquer experiência que envolva emoções é gravada na memória afetiva de cada pessoa criando uma relação das vivências passadas com atividades do cotidiano" e essas experiências podem ocorrer através de objetos.

Agora fechem os olhos imaginem a quantidade de objetos que nos rodeiam, ao acordarmos, por exemplo, estamos numa cama envolvida por inúmeros objetos como colchão, lençol, travesseiro, fronha, cobertor, fora o que está no criado-mudo se houver um, objetos que passam todos os dias a nossa volta, num momento muito importante da nossa rotina que é quando vamos dormir e descansar após um longo dia vivido.

Estes objetos possuem significados e passam algumas vezes, despercebidos por nós, por fazerem parte desta rotina, isto que esse foi só um exemplo básico de uma situação habitual que acontece diariamente com a maioria da população.

O filósofo e historiador polonês Pomian afirma em uma de suas obras que "se se tentasse fazer o inventário do conteúdo de todos os museus e de todas as coleções particulares, mencionando apenas uma vez cada categoria de objetos que aí se encontram, um livro grosso não seria suficiente" (PO- 
MIAN, 1984, p. 51), logo, pode-se concluir que vivemos rodeados de objetos.

Dohmann explica que "o objeto traduz em sua materialidade a intenção do ato preexistente que Ihe deu origem, e sua forma é produto de uma performance imaginada até mesmo antes de sua própria configuração física" (DOHMANN, 2010, p. 71). E quando falamos em objetos e seus significados, ainda soa de uma forma muito ampla, mas há quem diga que os objetos possuem classificações mais complexas, Pomian faz essa classificação em três categorias:

\section{C Existem pelo menos três situações possíveis: uma coisa tem apenas utilidade sem ter significado algum; um semióforo tem apenas o significado de que é o vetor sem ter a mínima utilidade, mas existem também objetos que parecem ser ao mesmo tempo coisas e semióforos (POMIAN, 1984 p. 72).}

As coisas são vistas como objetos úteis e sem significados, e os semióforos não possuem utilidade, mas são dotados de significados, e há também a mistura dos dois, que seria o caso do objeto pessoal da autora, um tabuleiro de xadrez como mostra a figura 1:

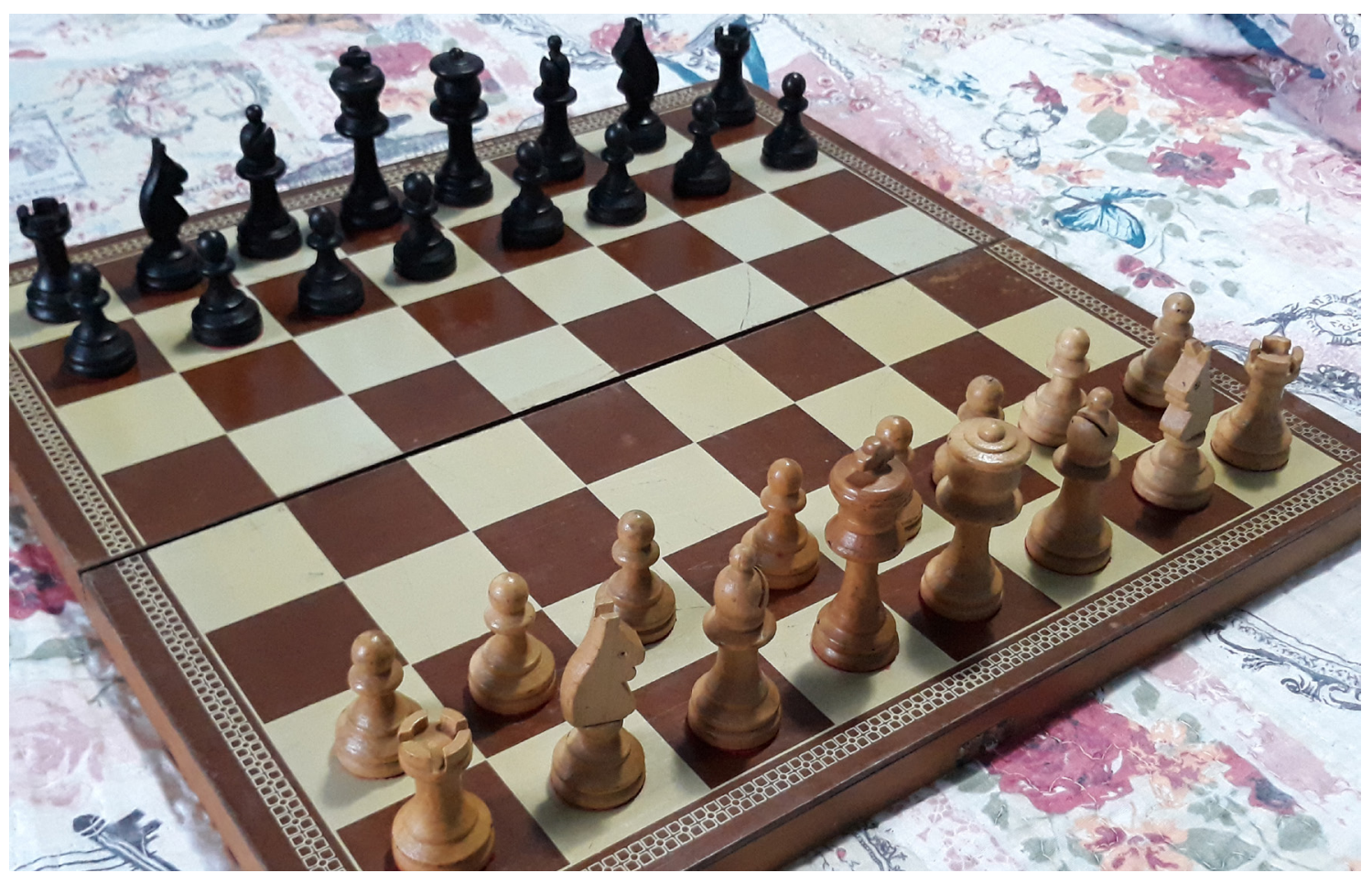

Figura 1: Tabuleiro de xadrez. Fonte: Elaborada pela autora. 
Este tabuleiro o pai da autora comprou no ano em que ela nasceu, quando ela cresceu, ele ensinou-a a jogar, e hoje em dia o tabuleiro é dela e possui toda carga emocional dos momentos compartilhados entre os dois na infância, ela guarda-o com muito carinho e ao mesmo tempo uso ele para jogar.

Quanto ao design emocional, há três níveis que podem ser trabalhados de acordo com Norman (2008), o visceral que é relacionado à aparência do objeto, o comportamental que é vinculado ao prazer e a efetividade do uso do objeto, e o reflexivo que é ligado à satisfação pessoal e as lembranças que o objeto pode trazer. Neste artigo vamos abordar sobre o nível reflexivo que é onde residem os mais altos níveis de sentimentos e emoções.

Enquanto os dois primeiros níveis referem-se ao tempo presente, o nível reflexivo faz pensar no passado, Norman (2008) diz que "o nível reflexivo se estende por muito mais tempo - por meio da reflexão você se lembra do passado e considera o futuro" (NORMAN, 2008, p. 58) e é exatamente esse momento de reflexão que faz com que um objeto possa adquirir significados e tornar-se um semióforo.

Acredita-se que através dos questionários aplicados como procedimento metodológico e das fotos dos objetos pessoais recebidas pelos participantes, grande parte delas trata-se de semióforos para seus donos, objetos que poderiam sim ter uma utilidade, mas que eles descartam usar, restando apenas o significado atribuído.

Pomian exemplifica "as fechaduras e as chaves que não fecham nem abrem porta alguma, as máquinas que não produzem nada, os relógios de que ninguém espera a hora exata" (POMIAN, 1984, p. 51), mas são objetos que ninguém ousa descartar, mesmo sem ter a funcionalidade inicial.

Abaixo se pode observar a figura 2 recebida de um dos participantes, que a princípio é considerada uma coisa por ter a função de broche e poder ser usado como tal, porém, pela sua dona ter lhe atribuído significado emocional e não usá-lo como broche, ele passa a ser semióforo. 


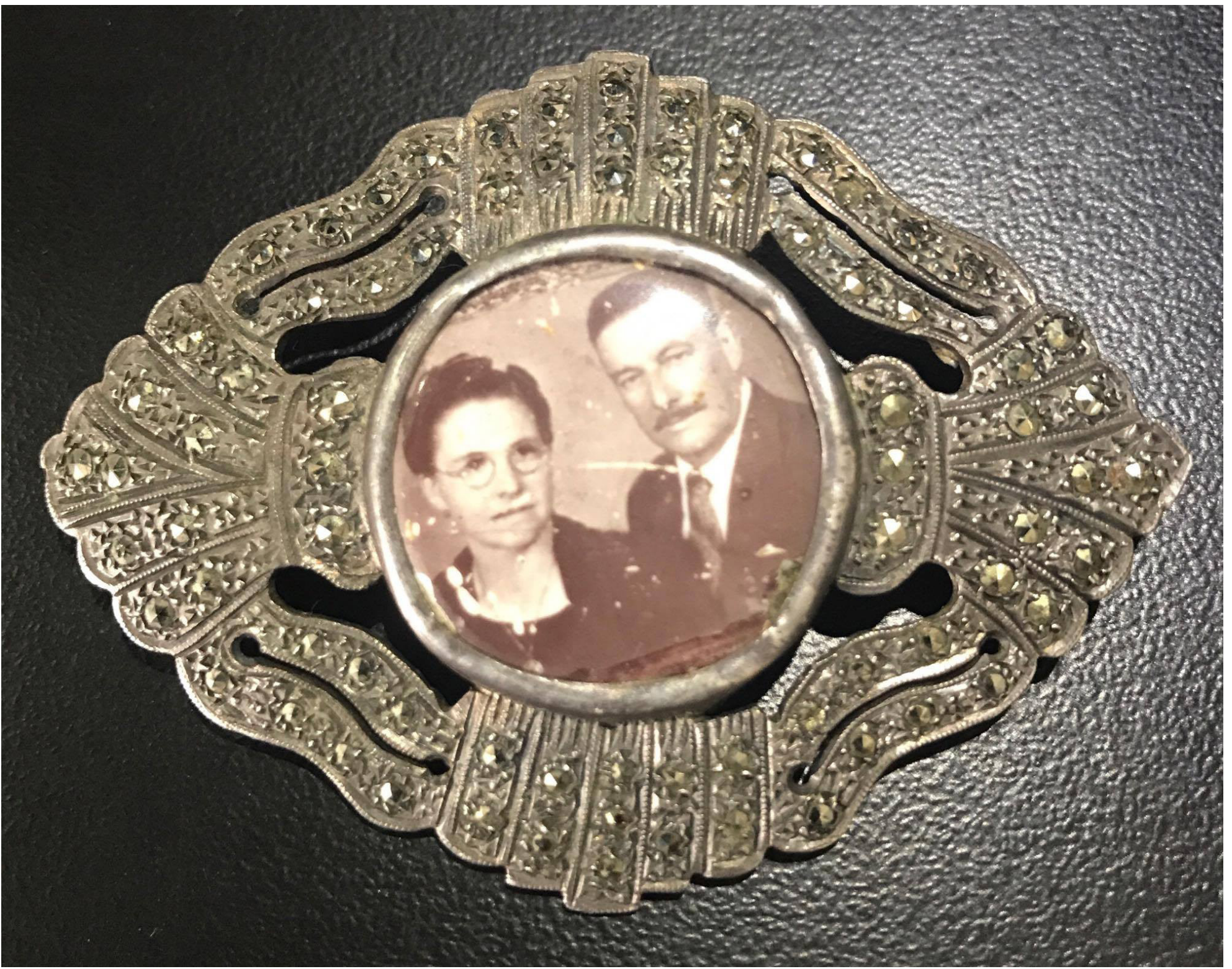

Figura 2: Broche de família. Fonte: Questionário aplicado de forma anônima.

Portanto, o broche acima nasceu coisa, mas no momento em que não foi mais usado para o fim que foi criado ele virou semióforo, porém, a qualquer momento ainda pode ser coisa e estar sendo utilizado para sua função original.

A participante conta que o broche possui a foto das bodas de prata da sua bisavó e quando ela veio a falecer, foi passado para sua avó e agora está sob seus cuidados, e foi usado como broche em eventos pontuais como para enfeitar o buque do seu casamento, como pode ser observado na figura 3 e para a produção de editoriais de moda como pode ser visto nas figuras 4 e 5 : 


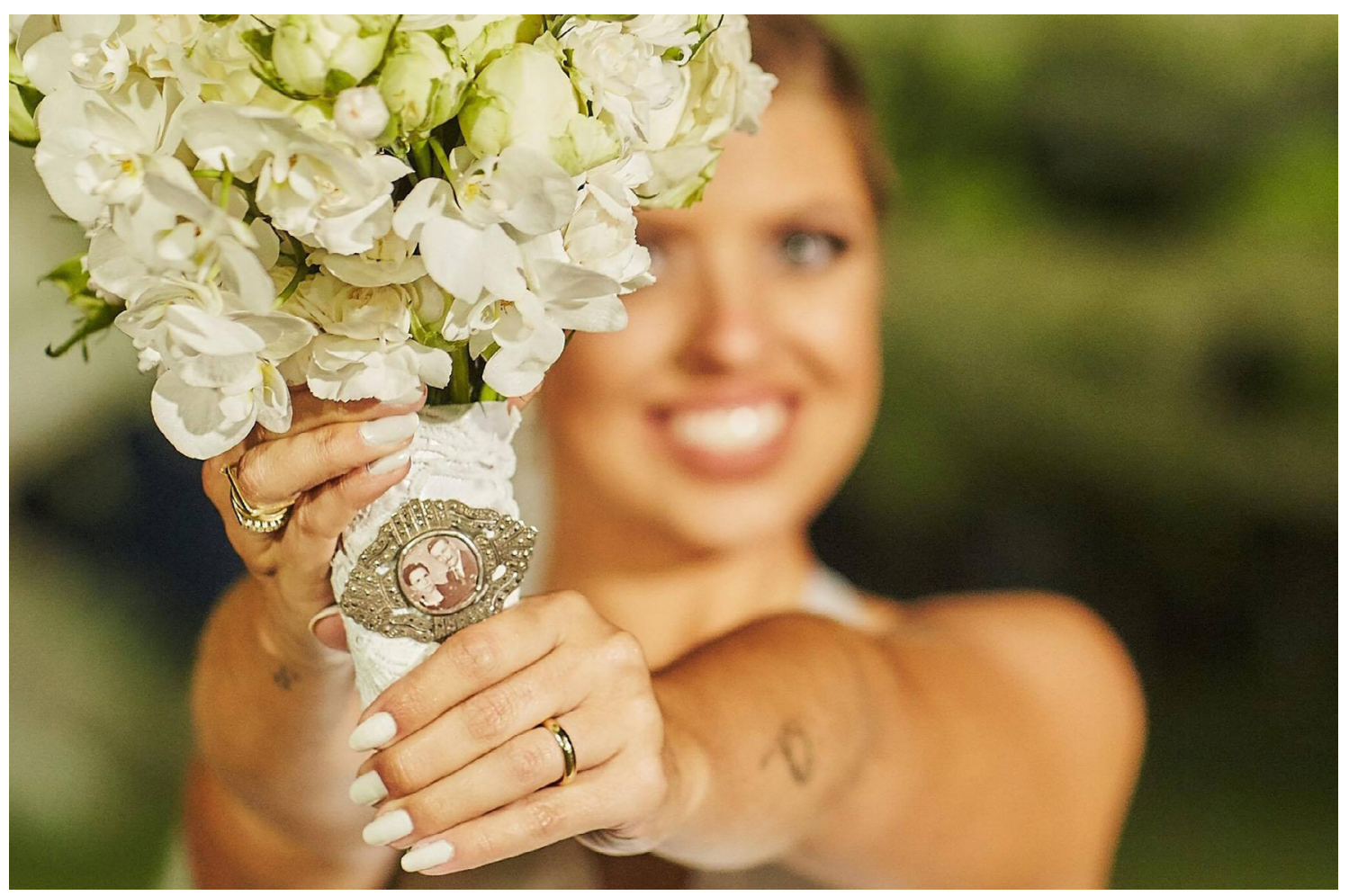

Figura 3: Buque do casamento. Fonte: Questionário aplicado de forma anônima.

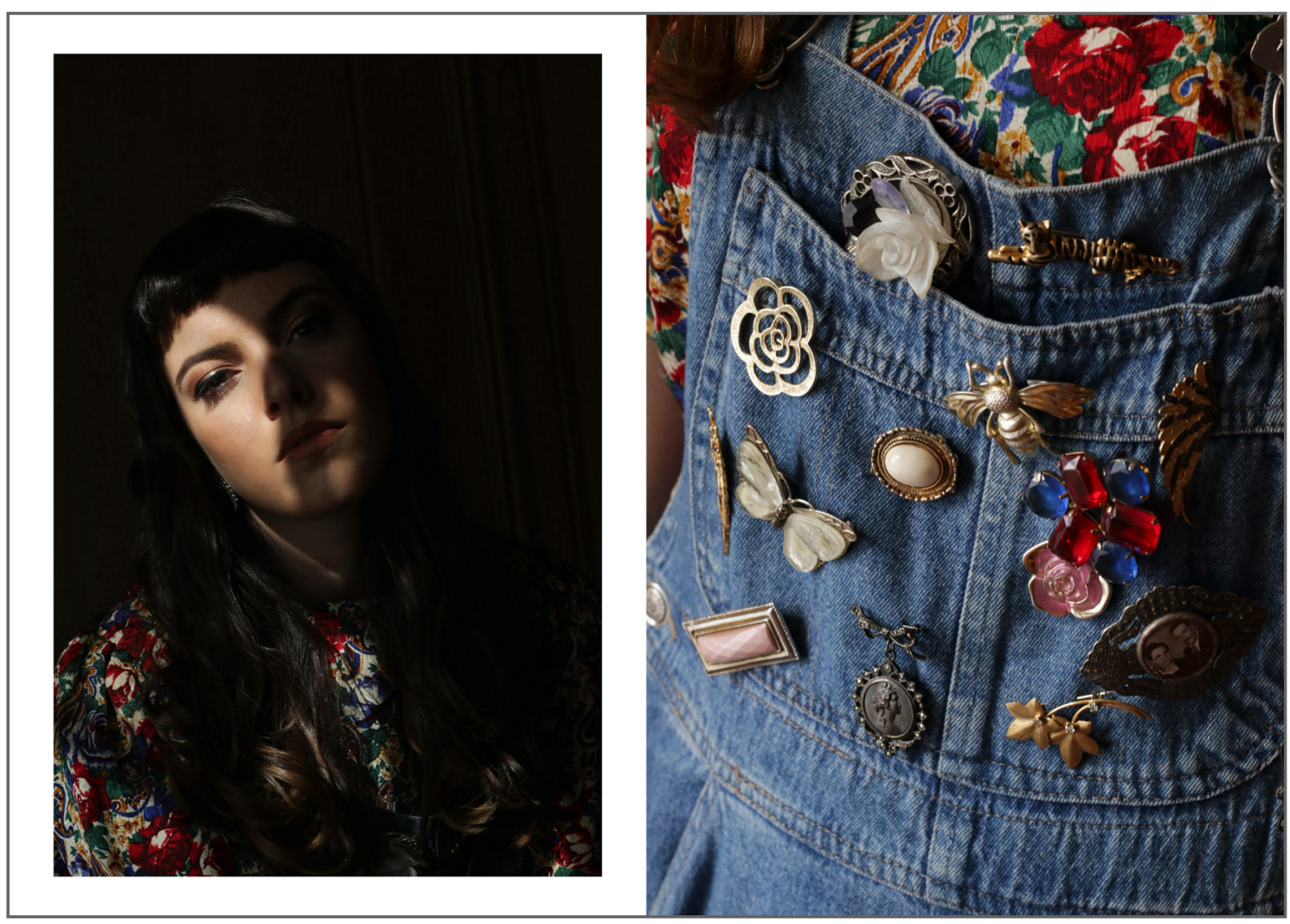

Figura 4: Broche usado para a produção do editorial de moda Memória Trajada. Fonte: Frantieska Schneid. 


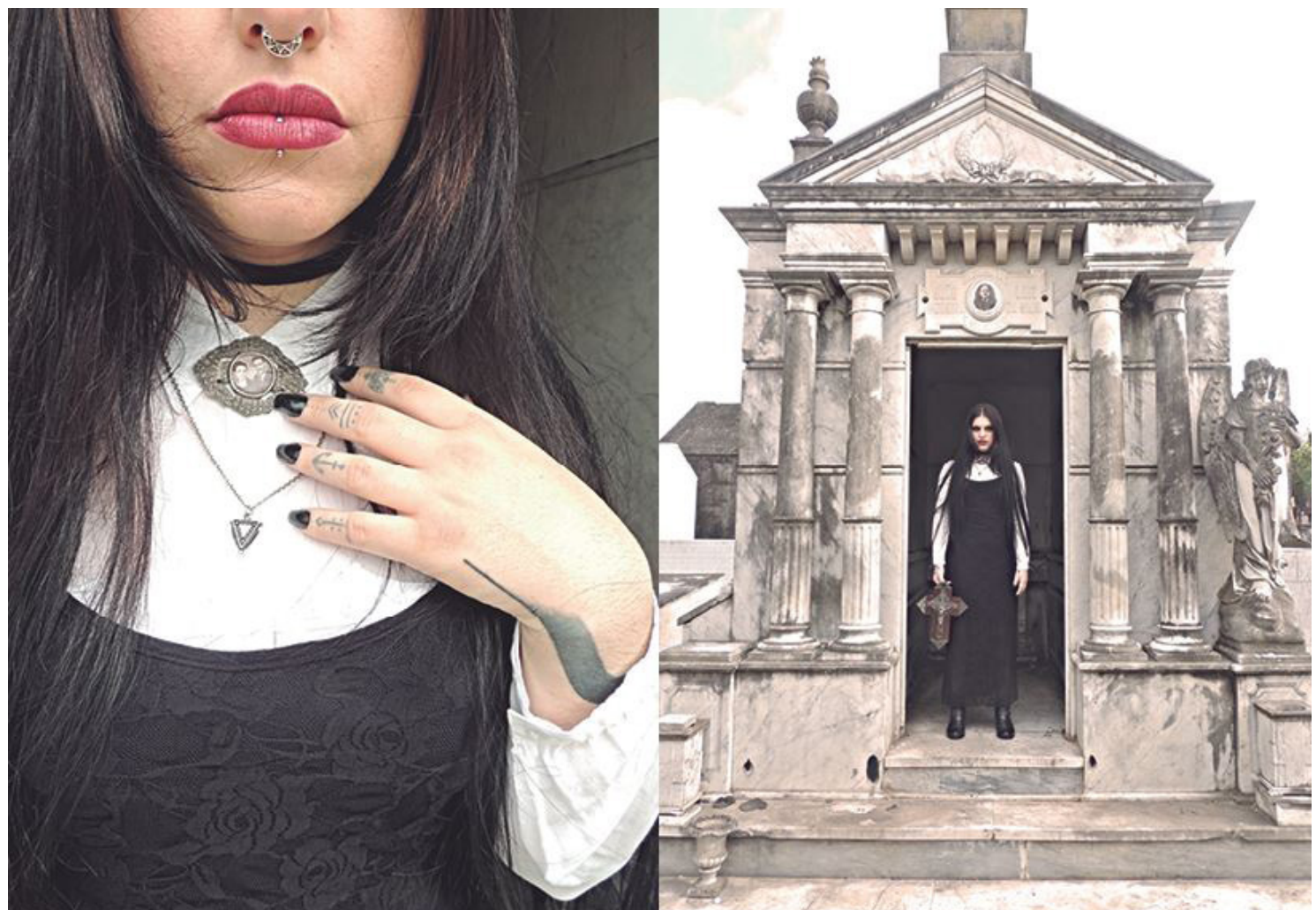

A participante conta também em uma das suas respostas que o broche é um objeto que tem um espaço especial em sua memória afetiva, sendo um evocador de memórias, por isso atua como sua função utilitária esporadicamente, mas, que na maior parte do tempo é um semióforo para não ter grandes possibilidades de danificá-lo.

Os objetos são tão importantes quanto nossas memórias, eles integram nossa existência, em parte considerados coadjuvantes nos acontecimentos, quando não são os principais, tornando-se importantes fragmentos da memória.

Um bom exemplo do significado que um objeto possui, é quando o autor Stalybrass (2012) conta em "O casaco de Marx" que a esposa de seu amigo recém-falecido o presenteia com o casaco de Allon.

O casaco que o autor mais gostava, e agora possuía um significado que transcende a função de proteção que a veste possui, e o casaco passa a ter a função de resgatar memórias e gerar sentimentos, lembrar-se de momentos em que os dois amigos saiam juntos, entristecer-se por lembrar-se da perda do amigo, agora o objeto possuía um grande significado afetivo, totalmente diferente se o autor fosse a uma loja
Figura 5: Broche usado para a produção do editorial de moda 0 último retrato. Fonte: Frantieska Schneid. 
e comprasse um casaco igual ao do amigo, pois seria uma peça de roupa nova, sem carregar as vivências e os momentos eternizados junto de Allon.

O casaco pode estar usado, possuir marcas do tempo, mas mesmo assim há uma carga emocional tão grande que torna-o uma peça rara e cobiçada pelo amigo, sem nem pensar no design da peça, se é moda, se há tendências atribuídas a ela e isso é parte da reflexão inconsciente e do apego existente ao objeto, pois Norman fala que "no domínio dos sentimentos, é tão razoável se afeiçoar e amar coisas que são feias quanto o é não gostar de coisas que seriam chamadas de atraentes. As emoções refletem nossas experiências pessoais, associações e lembranças" (NORMAN, 2008, p. 68).

\section{CONSIDERAÇÕES FINAIS}

A partir dos relatos apresentados, pessoais, teóricos e de forma anônima através do questionário aplicado, possibilitou identificar como o design emocional está ligado a construção de memórias pessoais, demonstrando que objetos são fatores determinantes para que essa ligação seja realizada, percebemos o quanto os objetos podem adquirir valores sentimentais.

Além disso, conseguiu mostrar quais são os gatilhos para despertar as lembranças e sensações no exemplo do participante que falou de seu broche, de como foi adquirido, qual a história por trás, qual a importância dele hoje e de que forma é usado.

Essa conexão existente entre objeto e indivíduo confirma o valor dado a bens materiais sem relacionar a sua função inicial, mas sim pelo sentimento atribuído a ele, por ser algo singular, e pelos momentos e memórias despertadas em cima das reflexões e da evocação de lembranças por meio de objetos, servindo como compartilhadores de memórias e tornando-se a materialização do afeto, da emoção, da sensação. 


\section{REFERÊNCIAS BIBLIOGRÁFICAS}

DOHMANN, M. O objeto e a experiência material. Revista

Arte \& Ensaios, Rio de Janeiro, n. 20. p. 70-77, julho, 2010.

LORGUS, Alexandra Luiza; ODEBRECHT,

Clarisse. Metodologia de Pesquisa Aplicada

ao Design. Blumenau: Edifurb, 2011.

NORMAN, Donald. Design Emocional: por

que adoramos (ou detestamos) os objetos do

dia a dia. Rio de Janeiro: Rocco, 2008.

OLIVEIRA, Rômulo Linhares; WEBER, Karina

Pereira. Uma discussão sobre a utilidade do design

através do foco emocional. Revista Poliedro,

Pelotas, v. 1. n. 1. p. 101-111, abril, 2017.

POMIAN, Krzysztof. Coleção. In: Enciclopédia

Einaudi. v. 1: Memória História. Lisboa: Imprensa

Nacional-Casa da Moeda, 1984. p. 51-86.

STALLYBRASS, Peter. 0 casaco de Marx: roupas, memória, dor. - 4. Ed. Belo Horizonte: Autêntica Editora, 2012. 